\title{
Inhibition Efficiency of Some Amino Acids in the Presence of Vanillin for the Corrosion of Mild Steel in HCl Solution
}

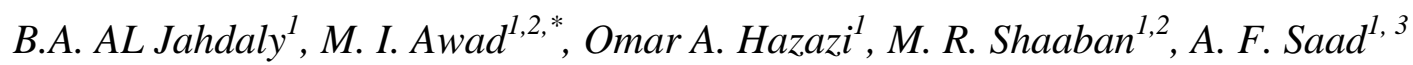 \\ ${ }^{1}$ Chemistry Department, Faculty of Applied Sciences, Umm Al-Qura University, Makkah Al- \\ Mukarramah, Saudi Arabia \\ ${ }^{2}$ Department of Chemistry, Faculty of Science, Cairo University, Cairo, Egypt \\ ${ }^{3}$ Chemistry Department, Faculty of Science, Assiut University, Assiut, 71516 Egypt. \\ *E-mail: $\underline{\text { mawad70@yahoo.com }}$
}

doi: $10.20964 / 2018.06 .50$

Received: 5 February 2018 / Accepted: 26 March 2018 / Published: 10 May 2018

The inhibition of corrosion of mild steel in $\mathrm{HCl}$ in the presence of vanillin (van) coexisting with some amino acids, i.e., valine (val), cysteine (cys), methylcysteine hydrochloride (m-cys) and methionine (meth) are compared. The possible synergistic inhibition of the corrosion by these amino acids using vanillin are also examined. It has been found that the inhibition efficiency of the studied amino acids in $\mathrm{HCl}$ is arranged as follows; meth $<$ m-cys $<$ cys $<$ val. In the presence of vanillin, the inhibition efficiencies are arranged as follows; m-cys < val < meth < cys. This arrangement of the inhibition efficiency is explained based on the possible synergistic adsorption of the studied amino acids with the pre-adsorbed chloride ions.

Keywords: Adsorption, Eco-friendly corrosion inhibitor, Synergism, Adsorption, Amino acids

\section{FULL TEXT}

(C) 2018 The Authors. Published by ESG (www.electrochemsci.org). This article is an open access article distributed under the terms and conditions of the Creative Commons Attribution license (http://creativecommons.org/licenses/by/4.0/). 